\title{
A MATERNIDADE NA PERSPECTIVA DE MÃES ADOLESCENTES
}

\author{
Motherhood from the perspective of teenage mothers
}

La maternidad en la perspectiva de madres adolescentes

Artigo Original

\section{RESUMO}

Objetivo: Compreender as repercussões da maternidade na perspectiva de mães adolescentes. Métodos: Estudo de campo, descritivo, com abordagem qualitativa. Desenvolvido no município de Pato Branco, Paraná, BR, no período entre novembro e dezembro de 2015. Participaram nove adolescentes, e os dados foram construídos por meio de entrevista semiestruturada. Os dados foram analisados e interpretados por meio da proposta operativa, emergindo três categorias temáticas. Resultados: Apontam que a categoria a descoberta da gravidez e a relação com a família evidenciou sentimentos como o medo de revelar aos pais e o receio de decepcioná-los diante da gravidez; a categoria uma relação de afetividade demonstra que apesar de todas as transformações e dificuldades enfrentadas pelas adolescentes, o envolvimento afetivo com o filho é traduzido nos sentimentos de amor, carinho e dedicação; e a categoria expectativas para o futuro demonstra as adaptações na vida social, familiar e escolar das participantes. Conclusão: $O$ estudo revelou que as mudanças iniciais com a descoberta da gravidez provocam desajustes emocionais na adolescente e com o decorrer do tempo há uma adaptação, demonstrando a importância do apoio familiar. Neste sentido, é perceptível que a família é o sustentáculo, é o porto seguro, o apoio na vida das adolescentes.

Descritores: Saúde do Adolescente; Adolescente; Gravidez na Adolescência.

\section{ABSTRACT:}

Objective: To understand the repercussions of motherhood from the perspective of teenage mothers. Methods: Qualitative descriptive field study conducted in the municipality of Pato Branco, Paraná, Brazil in the period between November and December 2015. Participants were nine teenagers and data were collected through semi-structured interviews. Data were analyzed and interpreted based on the operative proposal from which three thematic categories emerged. Results: The category The discovery of pregnancy and the relationship with the family highlighted feelings such as the fear of revealing to parents and the fear of disappointing them because of pregnancy; the category A relationship of affection demonstrates that despite all the changes and difficulties faced by teenagers, the affective relationship with the child is translated into feelings of love, care and devotion; and the category expectations for the future demonstrates adjustments in social, family and school life of the participants. Conclusion: The study revealed that the initial changes with the discovery of pregnancy cause emotional imbalance in the teenager, and over time there is an adjustment, showing the importance of family support. In this sense, it can be noted that the family is the mainstay, the safe haven and the support in the lives of teenagers.

Descriptors: Adolescent Health; Adolescent; Pregnancy in Adolescence.

\section{Ivete Maria Munslinger ${ }^{(1)}$ \\ Sandra Marçal da Silva ${ }^{(1)}$ \\ Cleunir de Fatima Candido De \\ Bortoli $^{(1)}$ \\ Kelly Bernardi Guimarães ${ }^{(1)}$}

1) Faculdade de Pato Branco - FADEP Pato Branco (PR) - Brasil

Recebido em: 06/04/2016

Revisado em: 20/06/2016

Aceito em: 01/08/2016 


\section{RESUMEN}

Objetivo: Comprender las repercusiones de la maternidad desde la perspectiva de madres adolescentes. Métodos: Estudio de campo, descriptivo de abordaje cualitativo desarrollado en el municipio de Pato Branco, Paraná, Brasil, en el periodo entre noviembre y diciembre de 2015. Participaron nueve adolescentes y los datos fueron construidos a través de entrevista semiestructurada. Los datos fueron analizados e interpretados a través de la propuesta operativa de la cual emergieron tres categorías temáticas. Resultados: Los resultados señalan que la categoría "la descubierta del embarazo y la relación con la familia" evidenció sentimientos como el miedo de revelar a los padres y el miedo de su decepción delante el embarazo; la categoría "una relación de afectividad" demuestra que a pesar de todas las transformaciones y dificultades afrontadas por las adolescentes, la relación afectiva con el hijo se traduce en los sentimientos de amor, cariño y dedicación; y la categoría "expectativas para el futuro" demuestra las adaptaciones en la vida social, familiar y escolar de las participantes. Conclusión: El estudio reveló que los primeros cambios con la descubierta del embarazo causan desajustes emocionales en la adolescente y con el tiempo hay una adaptación que demuestra la importancia del apoyo familiar. En ese sentido, es perceptible que la familia es el amparo, el puerto seguro, el apoyo en la vida de las adolescentes.

Descriptores: Salud del Adolescente; Adolescente; Embarazo en la Adolescencia.

\section{INTRODUÇÃO}

A Organização Mundial de Saúde (OMS), em sua definição de adolescência, inclui aspectos biológicos, sociais e psicológicos e delimita o período da vida entre os 10 e 19 anos $^{(1)}$. É neste ciclo da vida, em que o indivíduo passa por modificações significativas, as quais refletem no seu comportamento e nas suas relações com o outro, e consigo mesmo. Entre as transformações biológicas, estão as variações no corpo e o desenvolvimento dos caracteres sexuais secundários, em que, normalmente, surge o interesse pelo sexo e o início da vida sexual. Ao que se referem aos aspectos emocionais, as alterações envolvem o desenvolvimento da autoestima e da autocrítica, assim como indagações de valores dos seus pais e dos adultos de forma geral ${ }^{(2)}$.

Atualmente, observa-se sexarca precoce, estimulada por uma determinação da sociedade, que leva a criança a adolescer precocemente. $\mathrm{O}$ início precoce da atividade sexual pode representar muitas consequências, entre elas, a gravidez indesejada, levando a adolescente a adentar na vida adulta, mesmo sem uma maturidade psicológica e modificando o seu modo de vida ${ }^{(3)}$.
Ao compreender a sexualidade como um evento que aflora na adolescência, é desvelar um universo repleto de desejos, excitações, descobertas e sentimentos. Entretanto, é fundamental, que o tema seja abordado de forma adequada, mediado por uma educação sexual, possibilitando ao adolescente aprender sobre o cuidado com a sua vida reprodutiva e de seu parceiro, oportunizando que possam esclarecer suas dúvidas, medos e desejos ${ }^{(4)}$.

$\mathrm{Na}$ atualidade, a gravidez na adolescência é considerada um problema de saúde pública, com aumento significativo no mundo todo ${ }^{(5)}$. No Brasil, é um fenômeno amplamente discutido, e esse debate é movido pelas consequências de gestar neste ciclo da vida ${ }^{(3)}$. As suas implicações, no âmbito da saúde pública, englobam os aspectos sociais como o abandono escolar, consequentemente, a dificuldade de ingressar no mercado de trabalho, problemas no âmbito familiar e aumento da possibilidade de continuação do ciclo de pobreza ${ }^{(5)}$.

No Brasil, a taxa de fecundidade específica, compreendendo a faixa etária entre 15 e 19 anos, apresentou uma redução nos últimos anos, sendo que em 1990 ela representava 98 para cada mil adolescentes que tiveram filhos e, em 2007, uma taxa de $78^{(6)}$. Por outro lado, os dados do Departamento de Informática do Sistema Único de Saúde (DATASUS) demonstram números significativos de gestação na adolescência, correspondendo no ano de 2014 a 562.608 nascimentos, cuja idade das mães esteve entre 10 e $19 \operatorname{anos}^{(7)}$.

A vivência de uma gestação precoce e não planejada é muitas vezes repleta de importantes transformações, com implicações no ambiente familiar, levando a desajuste, impulsionando a família e a adolescente a reorganizarem seus projetos de vida, o que muitas vezes, resultando na interrupção dos estudos e abandono do trabalho ${ }^{(3)}$. No entanto, a maternidade na adolescência, apresenta diferentes perspectivas, pois os significados atribuídos a essa vivência dependem do contexto familiar e social em que a adolescente está inserida ${ }^{(8)}$.

As consequências da maternidade refletem negativamente mais nos aspectos biológicos e sociais da vida da adolescente. Ao mesmo tempo, proporciona sentimentos de felicidade e aceitação do novo papel social, instituindo um novo status e marcando uma nova etapa na vida da mulher ${ }^{(9)}$.

Diante do exposto, considerando que é fundamental a compreensão do evento da gravidez na adolescência e os diferentes aspectos envolvidos neste fenômeno. Ainda, buscando fornecer subsídios aos profissionais de saúde, em especial ao enfermeiro, para atuar na assistência integral à saúde da adolescente, orientando as mesmas frentes as adaptações enfrentadas neste período, justifica-se a relevância do tema. 
Para tanto, o estudo transcorreu impulsionado pela seguinte questão de pesquisa: Quais as repercussões da maternidade na adolescência? E para responder a esta questão, teve como objetivo compreender as repercussões da maternidade na perspectiva de mães adolescentes.

\section{MÉTODOS}

O caminho metodológico caracterizou-se por um estudo de campo ${ }^{(10)}$, descritivo com abordagem qualitativa ${ }^{(7)}$. A escolha pelo método qualitativo ocorreu pelo fato de ele ser utilizado nos estudos de história, das relações, das crenças, dos julgamentos que resultam das interpretações que os homens têm de seu modo de vida, suas construções, seus sentimentos e pensamentos. Configura-se dentro de investigações de grupos e segmentos delimitados e focalizados de contextos sociais ${ }^{(11)}$.

O cenário do estudo compreendeu uma unidade básica de saúde no município de Pato Branco, localizado na região sudoeste do Estado do Paraná - Brasil. Participaram do estudo nove adolescentes, que estavam vivenciando a maternidade. Utilizou-se como critérios de inclusão: ser adolescente, estar vivenciando a maternidade pela primeira vez e cujos filhos possuírem idade entre um mês até 19 meses. Como critérios de exclusão: ser gestante adolescente ou não possuir condições psicológicas para participar do estudo. A seleção das mães ocorreu por conveniência, sendo convidadas aquelas que compareceram na unidade.

Para construção dos dados, utilizou-se da técnica de entrevista semiestruturada, por meio de um roteiro elaborado pelas próprias pesquisadoras. Composta por duas etapas: na primeira, ocorreu o levantamento dos dados socioeconômicos (idade, escolaridade, situação conjugal, condições de moradia e a renda familiar); a segunda etapa foi constituída por questões orientadoras, de acordo com o objetivo do estudo: A) Conte-me como foi para você, a descoberta da gestação? B) Planejou e desejou esta gestação? C) Recebeu o apoio da família? do companheiro? da escola? D) Comente sobre as mudanças que aconteceram após o nascimento do seu filho. E) O que a maternidade/ seu filho significa para você? $\mathrm{O}$ encontro foi previamente agendado, e a entrevista realizada na própria residência das participantes.

Para registro de dados, os relatos foram gravados, posteriormente transcritos. A análise e a interpretação de dados ocorreram por meio da técnica de análise de conteúdo temática, pela proposta operativa, caracterizada por dois momentos operacionais: fase exploratória e fase interpretativa $^{(11)}$.

No primeiro momento, buscou-se pela compreensão do contexto socio-histórico do grupo social investigado, levantando a história do grupo, o ambiente onde as adolescentes estavam inseridas, caracterizando o contexto em que o estudo foi desenvolvido ${ }^{(11)}$.

O segundo momento operacional, buscou-se nos relatos o sentido, a lógica interna, as projeções e as interpretações. Esta fase apresentou-se em duas etapas: na ordenação dos dados: incluiu a transcrição do material, a releitura, a organização dos relatos e dos dados coletados. Na classificação dos dados: realizou-se a leitura horizontal e exaustiva dos textos, a leitura transversal com a categorização das unidades de sentido, buscando as conexões entre as mesmas ${ }^{(11)}$.

A análise final constitui o aprofundamento do material empírico composto nas etapas de ordenação e classificação e é considerado o ponto de partida e o ponto de chegada da compreensão e da interpretação; e na redação do relatório, é exposta a síntese e a comunicação dos dados. E por fim, a elaboração do relatório final deste estudo ${ }^{(11)}$.

Como resultado final, a análise de conteúdo resultou em três categorias temáticas, denominadas: A descoberta da gravidez e a relação com a família; uma relação de afetividade; e expectativas para o futuro.

Este estudo respeitou os preceitos éticos previstos na Resolução $n^{\circ}$. 466/2012, do Conselho Nacional de Saúde - Ministério da Saúde, que trata sobre pesquisa com seres humanos $^{(12)}$. Obteve aprovação pelo Comitê de Ética em Pesquisa com parecer $n^{\circ}$. 1.309.634. Foi assegurado o anonimato das participantes, sendo identificadas pelo sistema alfanumérico, de A1 a A9, seguindo a ordem das entrevistas. A coleta de dados iniciou somente após a assinatura do Termo de Consentimento Livre e Esclarecido, pelos pais ou responsáveis e a assinatura do Termo de Assentimento pelas participantes do estudo.

\section{RESULTADOS E DISCUSSÃO}

$\mathrm{Na}$ sequência, serão apresentados os dados socioeconômicos das participantes, formando uma caracterização do grupo e a seguir, as categorias temáticas, que emergiram após a análise de conteúdo dos relatos das adolescentes.

\section{Caracterização das participantes}

Participaram do estudo nove mães adolescentes, que estavam vivenciando a maternidade pela primeira vez e uma delas era mãe de gemelares. A idade das adolescentes era na faixa etária entre 14 anos e 18 anos, sendo que destas, três conviviam com companheiro, três delas eram solteiras e mantinham uma relação afetiva com o pai de seus filhos e três eram solteiras, sem relacionamento afetivo.

Em relação a moradia, identificou-se que sete delas continuam morando na mesma casa com os pais, padrastos 
e irmãos e duas moram com o companheiro. A renda familiar das participantes foi declarada pela maioria delas, entre dois a quatro salários mínimos, sendo que somente uma delas relatou possuir a renda entre cinco a seis salários mínimos. A maioria possuía dependência financeira dos pais, sendo identificado que oito das entrevistadas não trabalhavam. Quanto aos cuidados com o bebê, apenas uma declarou que estes eram realizados pelo pai e a madrasta, as demais, contavam com ajuda da família, porém eram as responsáveis pelos seus filhos.

Quanto ao fator escolaridade, cinco delas relataram que completaram o ensino fundamental, e quatro estão cursando o ensino médio. Sendo que, quatro das entrevistadas não estavam estudando e cinco continuam os estudos e estão pensando em concluir e ingressar no ensino superior.

\section{A descoberta da gravidez e a relação com a família}

Esta categoria evidencia que a experiência da gestação é uma transição de integração do desenvolvimento humano, no entanto, quando ocorre na adolescência, pode revelar complicações, que necessitam de reestruturação e reajustes em várias dimensões. $\mathrm{O}$ evento da gestação, por si só, já requer atenção especial, e, quando ocorre na adolescência, apresenta particularidades singulares, repleto de transformações que levam a um turbilhão de sentimentos, emoções e acontecimentos ${ }^{(13)}$.

A descoberta da gravidez pelas participantes foi revelada como um momento composto por uma mistura de sentimentos, como o medo de revelar para a família, o receio da decepção dos pais, desespero, dúvidas e incertezas em frente da situação, como mostram as falas a seguir:

Para mim foi tipo, eu não sabia o que fazer, depois fui me acostumando, mas ainda não tinha falado para minha mãe, quando eu contei para minha mãe ai me desesperei. A minha mãe ficou muito brava comigo, o meu pai também, eu me desesperei. (A3)

A família ficou muito assustada, mas depois foi se acostumando. (A4)

Na verdade, sempre soube só que escondi por um bom tempo. (A5)

Mais ou menos, no começo fiquei meio em dúvida... (fica pensativa) (A7)

Os achados corroboram com outros estudos que demonstram os conflitos vivenciados pelas adolescentes na descoberta da gravidez. Quando é um acontecimento indesejado, é imperioso o medo de enfrentar o ocorrido diante da família ou companheiro ${ }^{(13)}$. A descoberta da gestação repercute nos sentimentos, não somente da adolescente, mas também da sua família. Os membros reagem de diferentes formas, aflorando sentimentos de vergonha, desespero, constrangimentos, raiva, revolta, entre outros ${ }^{(14)}$.

A família desempenha papel fundamental no evento da gravidez na adolescência, através dela é possível compreender o fenômeno em suas múltiplas formas e significados. A compreensão está condicionada as suas crenças, costumes e expectativas traçadas para o futuro da adolescente $^{(15)}$.

Em diferentes contextos, é evidente que as dificuldades na relação familiar, limitam o diálogo com a adolescente a respeito da iniciação sexual e vivência da sexualidade. Criar espaços de diálogo com a adolescente, tanto nas escolas, com os profissionais de saúde, com os pais e com a comunidade, é possibilitar que ela compreenda abertamente a sua sexualidade. Este é um instrumento importantíssimo na resposta social às vulnerabilidades que envolvem a sexualidade na gestação, entre elas a gestação precoce e indesejada ${ }^{(3,4,15)}$.

Entretanto, é de suma importância reconhecer a situação atual da gravidez na adolescência, e suas implicações na sociedade e na vida dos indivíduos, tanto nos aspectos culturais, físicos, emocionais e psicossociais ${ }^{(16)}$. As mudanças, neste cenário, podem ser incentivadas por meio do empoderamento dos jovens, pelo conhecimento acerca da mobilização social e do reconhecimento dos seus direitos de assistência ética e integral ${ }^{(17)}$.

É notável o impacto da gravidez na adolescência, no âmbito familiar. Sendo uma questão observada, que afeta de forma mais expressiva a mãe da adolescente, prosseguindo com efeitos geralmente positivos, que acabam por repercutir em todos os membros da família, evoluindo com boa aceitação por parte de todos ${ }^{(3)}$.

Entre as entrevistadas, os relatos demonstram que o enfrentamento da família apresenta diferentes facetas. Prevalecem o estranhamento e a decepção em frente da gravidez precoce e indesejada, há uma mistura de sentimento. No entanto, os laços familiares conduziram a aceitação e encorajamento da adolescente, para enfrentar essa nova realidade, assimilando assim a nova trajetória da vida familiar.

A figura materna é revelada como o principal elemento da rede de apoio da adolescente na vivência desta experiência, que embora no início causasse o estranhamento, com o passar do tempo, as mães passam a representar importante referência para elas na compreensão da problemática vivenciada.

"Eu fiquei sozinha e ela (mãe) me apoiou sabe, me ajudou a não ficar em depressão, em ter meu filho sozinho, sem pai, nem nada”. (A5)

"Sim. Apoiou (mãe) em tudo, falaram que queriam ajudar o neném, acompanhar tudo, um apoio que todas as mães 
solteiras desejariam ter, mas nem todas são apoiadas". (A1)

"No começo a minha mãe ficou brava, mas depois ela se acostumou. Sem minha mãe não teria conseguido nem fazer o parto, porque desisti na hora, não queria fazer. Se ela não tivesse junto comigo eu não teria conseguido, agora ela me ajuda bastante também. "(A3)

A experiência da família com a descoberta da gravidez também faz parte da vivência da adolescente. No entanto, com o apoio familiar, e incumbindo-se de suas responsabilidades maternas, essa experiência contribui para o seu desenvolvimento pessoal ${ }^{(3)}$.

O apoio familiar é fundamental na construção da concepção da gravidez precoce. A forma como a família conduz o contexto da gestação, sua participação e apoio, em especial a relação mãe e filha, na identificação do papel materno e no desenvolvimento da criança $a^{(4)}$.

Entre as adolescentes, além do apoio materno, emergiram relatos do apoio do companheiro e da rede familiar, reforçando o amparo emocional na experiência da maternidade:

\section{"Recebi apoio só do meu namorado e mais ou menos da} minha mãe” (A6)

"Muita gente me julga insensivel pelo fato do meu filho morar com o meu pai e minha madrasta, mas sei que ele está bem e bem cuidado. Então, não me importa a opinião dos outros, quando quero ver meu filho vou lá e pronto, mato a saudade, mas sei que como mãe, que neste momento é muito melhor o meu filho estar lá com eles, ele está sendo bem cuidado e para ele é bem melhor lá neste momento (diz emocionada).” (A9)

Estudos revelam o papel que as mães, a rede familiar e os parceiros desempenham, na constituição da rede de apoio para, tanto afetivamente como financeiramente ${ }^{(8,18)}$. O desempenho do seu papel materno, nem sempre é exercido pelas adolescentes, que abdicam do filho, delegando a tutela e os cuidados aos genitores ${ }^{(19)}$. Quando os pais não exercem esse papel, os avós assumem as responsabilidades pelos netos e pelas filhas como iguais ${ }^{(20)}$.

\section{Uma relação de afetividade}

A categoria retrata a relação construída entre mãe e filho, quando questionadas sobre o significado da criança na vida delas, ficou evidente o forte vínculo afetivo estabelecido. Afirmam que, embora todas as modificações e dificuldades enfrentadas durante a gravidez, a chegada do filho contribuiu para que se tornassem mais maduras e conscientes das suas responsabilidades no desenvolvimento do filho. Demonstraram consciência da maternidade precoce, mas o envolvimento afetivo se sobrepõe e manifestam amor, carinho e dedicação quanto aos cuidados com o bebê.

Durante as entrevistas, as adolescentes manifestam satisfação e alegria no exercício da maternidade, mesmo reconhecendo as transformações com a chegada do filho. Alimentam um sentimento de amor maternal, com intensidade e prazer, projetando amor incondicional para seu bebê. Expressam a chegada da criança como um "presente de Deus", configurando sentimentos de agradecimento pela chegada e presença do (a) filho (a).

"Sem ela, eu não sei o que faria, se eu pudesse voltar no tempo eu ia fazer alguma coisa diferente. E se pudesse escolher ficar sem ela, escolheria ficar com ela”. (A3)

"Nossa, tudo de bom, a melhor coisa do mundo, a melhor coisa que aconteceu na minha vida foi ela. Um presente que Deus me deu, foi ela, não tem nem o que dizer." (A2)

Das nove entrevistadas, apenas uma manifestou características depressivas, relatando pensamentos suicidas, sentimento de insegurança quanto à criação da filha, uma vez que reconhecia a imaturidade e falta de recursos financeiros. Conta que foi sugerido que doasse a criança, no entanto o vínculo afetivo já estava estabelecido, o amor pela criança falou mais alto e decidiu enfrentar as dificuldades.

"Minha filha não tem explicação. Ela é tudo para mim, antes pensava em me matar, agora nem penso, tenho uma filha para criar e quero ver ela grande, bem grande, se formando e eu dando o melhor pra ela." (A5)

O significado do cuidado com o filho é evidente entre as mães adolescentes, retrata uma relação prazerosa, envolvendo o aprendizado e o fortalecimento do vínculo entre mãe e filho, que passa a representar o sentido único na vida delas. Cuidar na percepção delas é possibilitar o desenvolvimento e crescimento saudável, com afeto, amor e carinho, essenciais na formação da personalidade da criança $^{(21)}$.

O exercício da maternidade é descrito também em um estudo, como uma possibilidade de realização pessoal para as adolescentes, as quais demonstram orgulho pelo desenvolvimento dos filhos e o reconhecimento de mãe por eles. Entre os significados atribuídos aos filhos, está o vínculo estabelecido entre mãe e filho, de experienciar o amor em sua forma mais genuína, sustentado pela crença de uma relação duradoura entre ambos ${ }^{(22)}$.

\section{Expectativas para o futuro}

A presente categoria revela que a vida social das adolescentes entrevistadas apresentou muitas mudanças, relatam que houve a necessidade de adaptar-se à nova realidade, pois o bebê exige cuidados e atenção. Tornou- 
se necessário abdicar de algumas coisas que faziam parte do seu cotidiano, da sua rotina. Embora a escola facilitasse $\mathrm{o}$ atendimento às gestantes e licença maternidade, muitas interromperam os estudos, porém manifestam que pretendem voltar aos estudos após o crescimento dos filhos, bem como retornar ao trabalho, visto que apenas uma delas está trabalhando. Das participantes, seis pretendem continuar os estudos, ingressar no ensino superior, vislumbrando uma vida melhor, e melhores condições de trabalho.

"Espero estudar, voltar estudar e depois trabalhar." (A4) "A doutora falou se você não estuda depois o teu filho vai parar de estudar e você não tem que falar nada né, a minha mãe parou de estudar também posso parar, tem que dar exemplo." (A2)

"Estou estudando e pretendo fazer faculdade ainda não escolhi o curso, mas vou seguir em frente nos estudos, para que mais tarde meu filho sinta orgulho de ser filho de uma mãe mais nova." (A9)

"Então. Penso em voltar a estudar, até ele ficar maior." (A6)

Entre as que não demonstram interesse em voltar estudar, ficou evidente que a realidade social e econômica tem grande influência na perspectiva de vida e de ascensão social e econômica do sujeito. No entanto, é por meio da educação que ocorre a mobilidade social.

“Eu não quero voltar a estudar porque não compensa”.

"Pobre quando começa a fazer filho não para mais." (A7)

As diversas alterações com a gravidez precoce e indesejada implicam em transformações na vida social e econômica de toda a família, desencadeando abandono escolar e falta de estímulo para novas perspectivas profissionais. Isso corrobora com estudos, os quais revelam a frequência do abandono escolar no País entre adolescentes que vivenciam a experiência da maternidade ${ }^{(3,23)}$.

Entre as implicações, estão englobados os projetos sociais da adolescente, postergando as possibilidades de desenvolvimento da jovem. No exercício da maternidade na adolescência, o tempo desprendido em suas ações compromete o período dedicado a uma preparação adequada para o futuro ${ }^{(3)}$.

\section{CONSIDERAÇÕES FINAIS}

O estudo realizado leva a compreensão dos impactos da gravidez na adolescência, nos diferentes aspectos, tanto social quanto emocional. O desenvolvimento do estudo proporcionou revelar que as transformações iniciais com a descoberta da gravidez provocam desajustes emocionais na adolescente e, com o decorrer do tempo, há uma adaptação, evidenciando-se a importância do apoio familiar. Neste sentido, é perceptível que a família é o sustentáculo, é o porto seguro, o apoio na vida das adolescentes. É o núcleo familiar que transmite segurança na vivência desta fase, uma vez que as adolescentes necessitam de apoio financeiro para o sustento, apoio emocional para enfrentar as modificações e apoio quanto aos cuidados com o bebê.

É notório que mediante todas as adversidades de uma gravidez precoce e indesejada, as adolescentes estabelecem forte vínculo afetivo com os bebês. Há uma relação de conflito de identidade, precisam amadurecer precocemente, assumindo responsabilidades e deixando de lado vivências naturais da adolescência. E neste contexto, destacou-se a figura da mãe, como principal apoio a elas e repercutindo no papel materno desenvolvido por elas.

Além do campo familiar, outras instâncias precisam envolver-se, assumindo as especificidades de atuação, e assim contribuir para que a adolescente possa dar continuidade no processo de formação pessoal e social. Partindo deste parâmetro é fundamental que os serviços de saúde, a educação e a assistência social realizem um trabalho efetivo de apoio, encaminhamento e orientação sobre a relação presente e futura da adolescente na vida social e profissional.

A gravidez na adolescência é uma realidade, sendo, portanto, necessário o estabelecimento de políticas públicas voltadas para a prevenção e atendimento integral para a adolescente e a criança, ressaltando que deve ser um trabalho em rede, no qual as diversas esferas de atendimento estabeleçam um diálogo, na busca de alternativas para atender as necessidades individuais. Sendo que as contribuições do presente estudo podem ser relevantes para a prática do profissional enfermeiro, em suas ações de atenção à saúde da adolescente e, por meio da educação em saúde, possa promover a vivência e o exercício da sexualidade na adolescência, de forma segura e consciente.

\section{REFERÊNCIAS}

1. Pariz J, Mengarda CF, Frizzo GB. A atenção e o cuidado à gravidez na adolescência nos âmbitos familiar, político e na sociedade: uma revisão da literatura. Saude Soc [Internet]. 2012 [acesso em 2016 Ago 07];21(3):623-36. Disponível em: http:// www.scielo.br/scielo.php?script=sci_arttext\&pid=S01 0412902012000300009\&lng=en

2. Souza TA, Brito MEM, Frota AC, Nunes JM. Gravidez na adolescência: percepções, comportamentos e experiências de familiares. Rev Rene. 2012;13(4): 794-804. 
3. Nascimento MG, Xavier PF, Sá RDP. Adolescentes grávidas: a vivência no âmbito familiar e social. Adolesc Saúde. 2011;8(4):41-7.

4. Santos CAC, Nogueira KT. Gravidez na adolescência: falta de informação? Adolesc Saúde. 2009;6(1):48-56.

5. Taveira AM, Santos LA, Araújo A. Perfil das adolescentes grávidas do município de São Gonçalo do Pará/MG. Rev Enferm Cent.-Oeste Min. 2012;2(3): 326-36.

6. Ministério da Saúde (BR), Secretaria de Atenção em Saúde. Diretrizes nacionais para a atenção integral à saúde de adolescentes e jovens na promoção, proteção e recuperação da saúde. Brasília: Editora do Ministério da Saúde, 2010.

7. Ministério da Saúde(BR), Departamento de Informática do SUS [Internet]. Brasília: Datasus [acesso em 2016 Ago 06] Disponível em: http://tabnet.datasus.gov.br/ cgi/deftohtm.exe?sinasc/cnv/nvuf.def

8. Resta DG, Marqui ABT, Colomé ICS, Jahn AC, Eisen C, Hesler LZ, et al. Maternidade na adolescência: significado e implicações. REME Rev Min Enferm. 2010;14(1):68-74.

9. Trajano MFC, Quirino GS, Gonçalves GAA. Consequências da maternidade na adolescência. Cogitare Enferm. 2012;17(3):430-6.

10. Gil AC. Como elaborar projetos de pesquisa. $4^{\mathrm{a}}$ ed. São Paulo: Atlas; 2008.

11. Minayo MCS. O desafio do conhecimento: pesquisa qualitativa em saúde. 14ª ed. São Paulo: Hucitec; 2014.

12. Ministério da Saúde (BR). Resolução no 466, de 12 de dezembro de 2012, do Conselho Nacional de Saúde. Dispõe sobre pesquisa envolvendo seres humanos. Brasília: Comissão Nacional de Ética em Pesquisa (CONEP); 2012.

13. Magalhaes MTM, Souza VD, Oliveira QMV, Bessa JMS. Conflitos vivenciados pelas adolescentes com a descoberta da gravidez. Rev Esc Enferm USP. 2008;42(2):312-20.

14. Valila MG, Moraes NA, Dalbello NN, Vieira SS, Beretta MIR, Dupas G. Gravidez na Adolescência: Conhecendo a experiência da família. Reme Rev Min Enferm. 2011;15(4):556-66.

15. Hoga LAK, Borges ALV, Reberte LM. Razões e reflexos da gravidez na adolescência: narrativas dos membros da família. Esc. Anna Nery Rev Enferm. 2010;14(1):151-7.
16. Souza AXA, Shelva MN, Coutinho MPLS. Representações sociais de adolescentes grávidas sobre a gravidez na adolescência. Psicol Soc. 2012;24(3): 588-96.

17. Teixeira SCR, Silva LWS, Teixeira MA. Políticas públicas de atenção às adolescentes grávidas - uma revisão bibliográfica. Adolesc Saúde. 2013;10(1):37-44.

18. Schwartz T, Vieira R, Geib LTC. Apoio social a gestantes adolescentes: desvelando percepções. Ciênc Saúde Coletiva. 2011 [acesso em 2015 Jun 11];16(5):2575-85.

19. Silva DV, Salomão NMR. A maternidade na perspectiva de mães adolescentes e avós maternas dos bebês. Estud Psicol. 2003;8(1):135-45.

20. Oliveira ARV, Vianna LG, Cárdenas CJ. Avosidade: Visões de avós e de seus netos no período da infância. Rev Bras Geriatr Gerontol. 2010;13(3):461-74.

21. Araújo CIS, Lima FCR, Moita GWSB, Rocha SS, Santos TMMG. A mãe adolescente e o cuidado ao recém-nascido. Rev Interdisciplinar Novafapi. 2011;4(3)14-9.

22. Gontijo DT, Medeiros M. "Tava morta e revivi": significado de maternidade para adolescentes com experiência de vida nas ruas. Cad Saúde Pública. 2008;24(2):469-72.

23. Silveira RE, Santos AS. Gravidez na adolescência e evasão escolar: revisão integrativa da literatura. Rev Enferm Atenção Saúde. 2013;2(1):89-98.

\section{Endereço do primeiro autor:}

Ivete Maria Munslinger

Faculdade de Pato Branco - FADEP

Rua Benjamin Borges dos Santos, 1100

Bairro: Fraron

CEP: 85503-350 - Pato Branco - PR - Brasil

E-mail: ivetemariamunslinger@outlook.com

\section{Endereço para correspondência:}

Cleunir de Fatima Candido De Bortoli

Faculdade de Pato Branco - FADEP

Rua Benjamin Borges dos Santos, 1100

Bairro: Fraron

CEP: 85503-350 - Pato Branco - PR - Brasil

E-mail: cleunir_candido@hotmail.com 